\title{
Prediction of lightning flash density with the WRF model
}

\author{
B. Lynn ${ }^{1,2}$ and Y. Yair ${ }^{3}$ \\ ${ }^{1}$ The Hebrew University of Jerusalem, Jerusalem, Israel \\ ${ }^{2}$ Weather-It-Is, Efrat, Israel \\ ${ }^{3}$ The Open University of Israel, Ra' anana, Israel
}

Received: 30 March 2009 - Revised: 10 January 2010 - Accepted: 13 January 2010 - Published: 17 February 2010

\begin{abstract}
The Lightning Potential Index (LPI) is a measure of the potential for charge generation and separation that leads to lightning flashes in convective thunderstorms. It is calculated from model simulated updraft and microphysical fields. It was designed to predict the potential of lightning occurrence in operational weather forecasting models, but could possibly be used to improve short-range forecasts of heavy rain. The index is modified here to be model grid-scale transparent between 1 and $4 \mathrm{~km}$ (the approximate upper limit of explicit microphysical weather forecasts). Two case studies show that the modification appears to work quite well, and that LPI can be calculated on both an extremely high resolution research-grid (i.e., $1.33 \mathrm{~km}$ ) and high resolution (i.e., $4 \mathrm{~km}$ ) operationally compatible forecast grid. Analytical expressions are presented to use the LPI to predict the hourly lightning flash density.
\end{abstract}

\section{Introduction}

Lightning is a characteristic of severe weather and often accompanies large hail and torrential rains, which under certain circumstances (terrain type, slope, drainage, soil saturation) can turn into flash floods. It is also a natural hazard by itself, with potential lethal consequences to human life and considerable damages to electrical infrastructures and aviation. The need for lightning prediction is clear and indeed many real-time lightning detection systems are now able to accurately determine the impact location of cloud-to-ground lightning (see review in Sect. 6.10 in MacGorman and Rust,

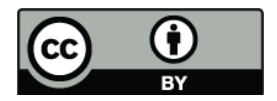

Correspondence to: B. Lynn

(yoavya@openu.ac.il)
1998). There has been, however, a much lower capability to forecast the potential for lightning occurrence in short-range forecasts. Although several indices are used by meteorologists to forecast the probabilities of thunderstorms (such as LI, KI, CAPE and CPTP), they are not based on the microphysics of charge separation in thunderstorms and rely on thermodynamic instability parameters, thus resulting in coarse scale outputs.

Recently Lynn and Yair (2008) and Yair et al. (2010) described the development and utilization of the Lightning Potential Index (LPI), a new index for evaluating the potential for lightning activity from weather forecast model output data. Yair et al. (2010) showed that the LPI correlates positively with observed lightning density and also heavy rainfall. They suggested that the LPI could be used to predict the potential for the occurrence of lightning, and reasoned that it may be used as an intermediary to improve short-range forecasts of heavy rain through comparing observed lightning to model calculated LPI intensity and location. The LPI is calculated within the charge separation region of clouds between $0^{\circ}$ and $-20^{\circ} \mathrm{C}$, where the non-inductive mechanism by collisions of ice and graupel particles in the presence of super-cooled water is most effective (see extensive review of charge separation mechanisms operating in thunderstorms by Saunders, 2008). Although the LPI is an empirical equation, it consists of cloud-physical parameters - so the LPI as a measure of the potential for electrical activity should be location independent.

Yair et al. (2010) used the Weather Research and Forecasting Model (i.e., WRF; Skamarock, 2005) with explicit microphysics at $1 \mathrm{~km}$ grid resolution. However, it is still impractical to make operational weather forecasts using $1 \mathrm{~km}$ grid resolution due to the demands of computational resources. Instead, the WRF is run, for example, using $4 \mathrm{~km}$

Published by Copernicus Publications on behalf of the European Geosciences Union. 
grid resolution twice a day over the Continental US, while other operational forecast centers use 3 or $4 \mathrm{~km}$ grid resolution. The present paper suggests how to modify the LPI from its current formulation so as to become grid-scale "transparent" between 1 and $4 \mathrm{~km}$ grid resolution. It also uses observations and model calculated LPI to derive equations that can be used to predict lightning density.

\section{Model description}

\subsection{The Lightning Potential Index (LPI)}

The LPI is defined as the volume integral of the total mass flux of ice and liquid water within the "charging zone" ( 0 to $-20^{\circ} \mathrm{C}$ ) in a developing thundercloud. It portrays the potential of the thundercloud to separate electrical charge in the relevant depth via the non-inductive ice-graupel mechanism, but it does not calculate the resultant electric field or its evolution. It is derived from the model simulated grid-scale updraft velocity and the mass mixing-ratios of liquid water, cloud ice, snow, and graupel. This approach is in line with many studies showing strong and consistent relationships between lightning flash rates (that can be integrated in time to give total lightning) and the presence of small ice and high precipitation rates (Petersen and Rutledge, 1998; Sherwood et al., 2006). Deierling et al. (2008) and Deierling and Petersen (2008) showed that the updraft volume in the charging zone (at temperatures below $-5^{\circ} \mathrm{C}$ ) was highly correlated with total lightning activity. Recent modeling work by McGorman et al. (2008) showed that the relationships of total flash rates with rain mass, ice crystal mass flux, and graupel volume are significant $(>0.65)$, while weak correlation $(0.3)$ is found between maximum flash rate and maximum updraft. Wiens (2008) summarized numerous studies during the STEPS campaigns, combining remote and in-situ measurements of cloud microphysical properties and the electrical behavior of the storm. Their main finding was that the total flash rate of the storm is strongly correlated with the graupel echo volume and also with the updraft volume.

These studies give strong experimental and observational support to the concept of the LPI, which in essence maps the fluxes of the main charging agents in thunderstorms. The LPI evolves with time since it is calculated from the microphysical and dynamical model fields at each time step and in every domain grid point. It is non-zero only within the charging zone, and furthermore the LPI for a particular model grid is only non-zero when a majority of cells within a 5 grid-radius of that grid point have a vertical velocity $>0.5 \mathrm{~m} \mathrm{~s}^{-1}$, indicating the growth phase of the thunderstorm. The LPI has the units of $\left[\mathrm{J} \mathrm{kg}^{-1}\right]$ and is defined by:

LPI $=1 / V \iiint \varepsilon w^{2} d x d y d z$

where $V$ is the model unit volume, $w$ is the vertical wind component in $\mathrm{ms}^{-1}$. The integral is computed within the cloud volume from the freezing level (altitude in $\mathrm{km}$ above the surface) to the height of the $-20^{\circ} \mathrm{C}$ isotherm; the model computed mass mixing ratios for snow $\left(q_{\mathrm{s}}\right)$, cloud ice $\left(q_{\mathrm{i}}\right)$ and graupel $\left(q_{\mathrm{g}}\right)$ are in units $(\mathrm{kg} / \mathrm{kg})$, and $\varepsilon$ is a dimensionless number which has value between 0 and 1 defined by:

$\varepsilon=2\left(Q_{\mathrm{i}} Q_{1}\right)^{0.5} /\left(Q_{\mathrm{i}}+Q_{1}\right)$

where $Q_{1}$ is the total liquid water mass mixing ratio in $(\mathrm{kg} / \mathrm{kg})$ and $Q_{\mathrm{i}}$ is the ice fractional mixing ratio in $(\mathrm{kg} / \mathrm{kg})$ defined by

$Q_{\mathrm{i}}=q_{\mathrm{g}}\left[\left(\left(q_{\mathrm{s}} q_{\mathrm{g}}\right)^{0.5} /\left(q_{\mathrm{s}}+q_{\mathrm{g}}\right)\right)+\left(\left(q_{\mathrm{i}} q_{\mathrm{g}}\right)^{0.5} /\left(q_{\mathrm{i}}+q_{\mathrm{g}}\right)\right)\right]$

In essence, $\varepsilon$ is a scaling factor for the cloud updraft, and attains a maximal value when the mixing ratios of super-cooled liquid water $\left(Q_{1}\right)$ and of the combined ice species $\left(Q_{\mathrm{i}}\right)$ are equal (note, $Q_{\mathrm{i}}$ is also obtains a maximal value when the mass mixing ratio of ice, snow, and graupel are equal). It signifies the fact that charge separation requires all these ingredients to operate synergistically within the charging zone, as shown by many laboratory experiments summarized by Saunders (2008).

One purpose of the study was to investigate the promise of using the LPI in operational forecast models. To this end the formulation used by Yair et al. (2009) was modified by multiplying it by the grid resolution in kilometers (divided by $1.33 \mathrm{~km}$; the base resolution). This is based on the continuity equation, assuming that the gradient of the horizontal wind is proportional to the vertical velocity divided by the length of a grid box. Simulation results from different case studies (not described here) of LPI ranging from a $1.33 \mathrm{~km}$ grid to those averaged to a $4 \mathrm{~km}$ grid (hosting the $1.33 \mathrm{~km}$ grid in a twoway nesting configuration) were analyzed, and it was found that such a relationship is a good approximation. Another goal of this study is to use the LPI to calculate the predicted lightning flash density. The method is described in the results section, and is based on the analysis presented there.

\section{Methodology}

\subsection{The Weather Research and Forecasting model (WRF)}

The WRF model is being used by many operational services for short and medium range weather forecasting. It is a fully compressible, non-hydrostatic atmospheric model, using a terrain-following hydrostatic vertical pressure coordinate. In recent years it has also become an accessible research tool, as it offers multiple physics options that can be flexibly combined in many ways (full formulation and documentation can be accessed through UCAR at: http://www.mmm.ucar. edu/wrf/users/pub-doc.html). In the present study, the model was initialized using reanalysis data from the Global Forecast Systems model (GFS), and the model simulations were for $24 \mathrm{~h}$. In total, there were four domains: Domain $1 \mathrm{had}$ 
$90 \times 90$ elements at $36 \mathrm{~km}$ grid resolution. Domain $2 \mathrm{had}$ $136 \times 136$ elements at $12 \mathrm{~km}$ grid resolution. Domain $3 \mathrm{had}$ $181 \times 181$ elements at $4 \mathrm{~km}$ grid resolution, and Domain 4 had $232 \times 232$ elements at $1 \mathrm{~km}$ grid resolution. There was two-way nesting between the grids. The model has run either using the first three grids (where the innermost grid was at $4 \mathrm{~km}$ ) or all four grids (where the innermost grid was at $1.33 \mathrm{~km}$ grids). The WRF Single Moment Scheme (Dudhia et al., 2009) was used for calculating the required parameters for computing the LPI.

The investigation included two cases, both of which had significant lightning activity and heavy rainfall. Case A was taken from the FLASH project data base, and constitutes a $24 \mathrm{~h}$ simulation of an early-fall flash flood that occurred in the Emilia Romagna region in north-western Italy, on 8 September 2006. Lightning activity in this event was very widespread, but was highly concentrated near the site of the flash flood. Case B was a winter-type heavy rain event in northern Israel which occurred on 28 February 2009, with the heaviest rain falling in the Lake Kinneret basin (Sea of Galilee).

\subsection{Lightning data}

For the Israeli case study, cloud-to-ground (CG) lightning locations obtained from the Israeli Electrical Company LPATS (Altaratz et al., 2003) were used, an array that includes 7 VLF antennas, dispersed over the country. The system detects cloud-to-ground lightning flashes that occur in Israel and up to $500 \mathrm{~km}$ from its borders, with a stated detection efficiency of $\sim 90 \%$; the unique network configuration of the LPATS detectors in Israel is dictated by the geography and results in almost a straight north-south line, which leads to detection minima in regions which are further out of the network coverage along this line. Specifically, the areas of southern Lebanon and the Gulf of Eilat in the Red Sea display a lower percentage of detection. Operationally, this system only detects cloud-to ground (CG) flashes and misses Intra-Cloud (IC) activity, and hence the total numbers of flashes reported in the various case studies in Israel is always lower than the actual lightning number. Despite this limitation the LPATS data properly represents the spatial distribution of lightning activity, as CG and IC flashes evolve together along the cloud life cycle (Altaratz et al., 2003).

For the Italian case study, data from the ZEUS European network were employed, which has good coverage of the central and western Mediterranean. This is a long-range lightning detection network with receivers located at 6 sites in Europe (Lagouvardos et al., 2009). The ZEUS receivers detect sferics discharges in the VLF frequency range (7$15 \mathrm{kHz}$ ) emitted by CG lightning and are capable of capturing up to 70 sferics per second. The location accuracy of ZEUS is of the order of $6 \mathrm{~km}$ over the Mediterranean region, and it is also capable of detecting some fraction of the intracloud flashes (IC), though the exact value may be hard to estimate. Further details on the ZEUS network can be found in Kotroni and Lagouvardos (2008).

\section{Results from the two case studies}

Figure 1 shows observed lightning and predicted LPI for each case study. A visual inspection shows that both the $1.33 \mathrm{~km}$ and $4 \mathrm{~km}$ grids predicted the size and locale of places where thunderstorms occurred in both events. Figure 2 shows the correlations between the values of LPI and the accumulated numbers of observed lightning flashes. Only data in the overlapping areas of the $1.33 \mathrm{~km}$ grids were used to calculate the correlations in each case. To obtain the data for these figures, the observed lightning flashes (from 00:00 UTC on each start date to 00:00 UTC on the next day) and values of LPI were time averaged (over the $24 \mathrm{~h}$ simulation), and then each was summed within each $36 \mathrm{~km}$ WRF outer grid and then area averaged. Thus there were $814 \mathrm{~km}^{2}$ and $7291.33 \mathrm{~km}^{2}$ WRF grid cells within the WRF $36 \mathrm{~km}$ grid over which the averaging was done.

There is a linear correlation between the lightning density (in units of flashes per $\mathrm{km}^{2}$ per hour) and the time-averaged values of computed LPI and in both case studies. The correlation values for the $1.33 \mathrm{~km}$ grid scale in case study A are slightly lower compared to the $4 \mathrm{~km}$ grid scale ( 0.39 vs. 0.46 ) while for case study B the opposite is true ( 0.71 vs. 0.65$)$. The most likely reason for the fact that the correlations are relatively low in the Italy case-study is because the model simulated less accurately the location of the strongest convection compared to the Israel case study. This is apparent from Fig. 1, where a spatial offset is evident.

Since one goal of the research was to derive a relationship between lightning density and the predicted LPI, both the lightning density and the LPI-averaged values were sorted in ascending order. This sorting removes any spatial information from the model data; it is "like" making a perfect forecast of convection, and assuming that high values of LPI correspond spatially (and implicitly in time) with high values of lightning density. Figure 3 shows a linear relationship $(R=0.98)$ between the sorted fraction of observed total lightning in Case A. In Case B, a second order regression equation $(R=0.95)$ had a higher correlation coefficient than an assumed linear relationship $(R=0.90)$. It is suggested that the concave appearance of the second order relationship between cloud-to-ground lightning density and LPI in the lower range of values of LPI is due to the fact that charge separation takes place in clouds some time before cloud-to-ground lightning activity occurs. The linear regression equation shown in Fig. 3 for observed fraction of total lightning can be used to calculate lightning density as a function of LPI in Case A, while the second order linear regression equation should be used in Case B to predict cloud-to-ground lightning. Note the first order accuracy of such a prediction depends on the forecast fidelity of the model simulation of convection and 

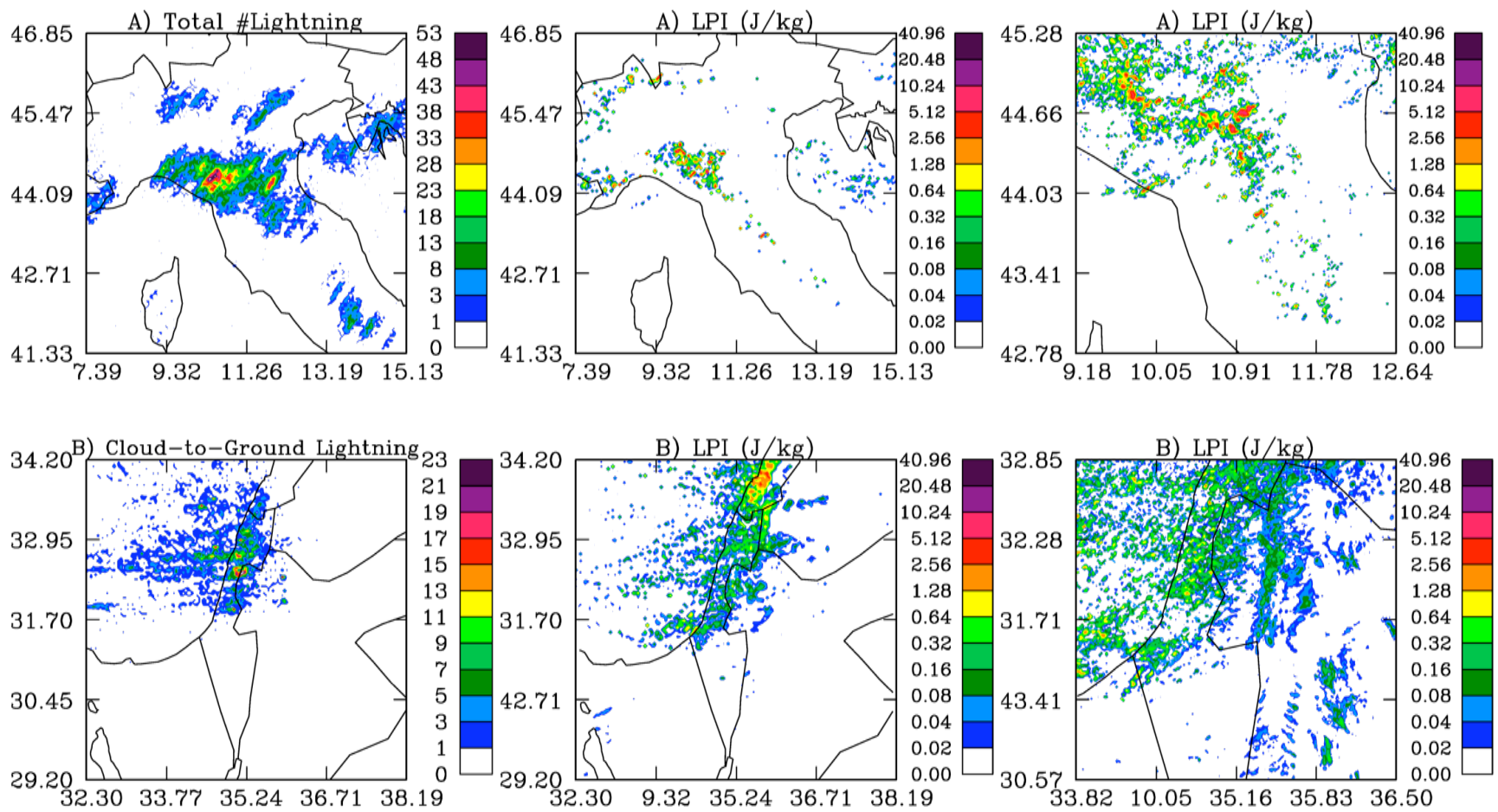

Fig. 1. Observed $24 \mathrm{~h}$ lightning is two case studies for Italy and Israel. The upper row is for case study (A) 9 September 2008 (ZEUS network), and the lower row for case study (B) 28 February 2009 (LPATS network), respectively. WRF model calculated, $24 \mathrm{~h}$ averaged, Lightning Potential Index (LPI) for both cases at $4 \mathrm{~km}$ (center) and $1.33 \mathrm{~km}$ (right) grid resolution for the same dates.
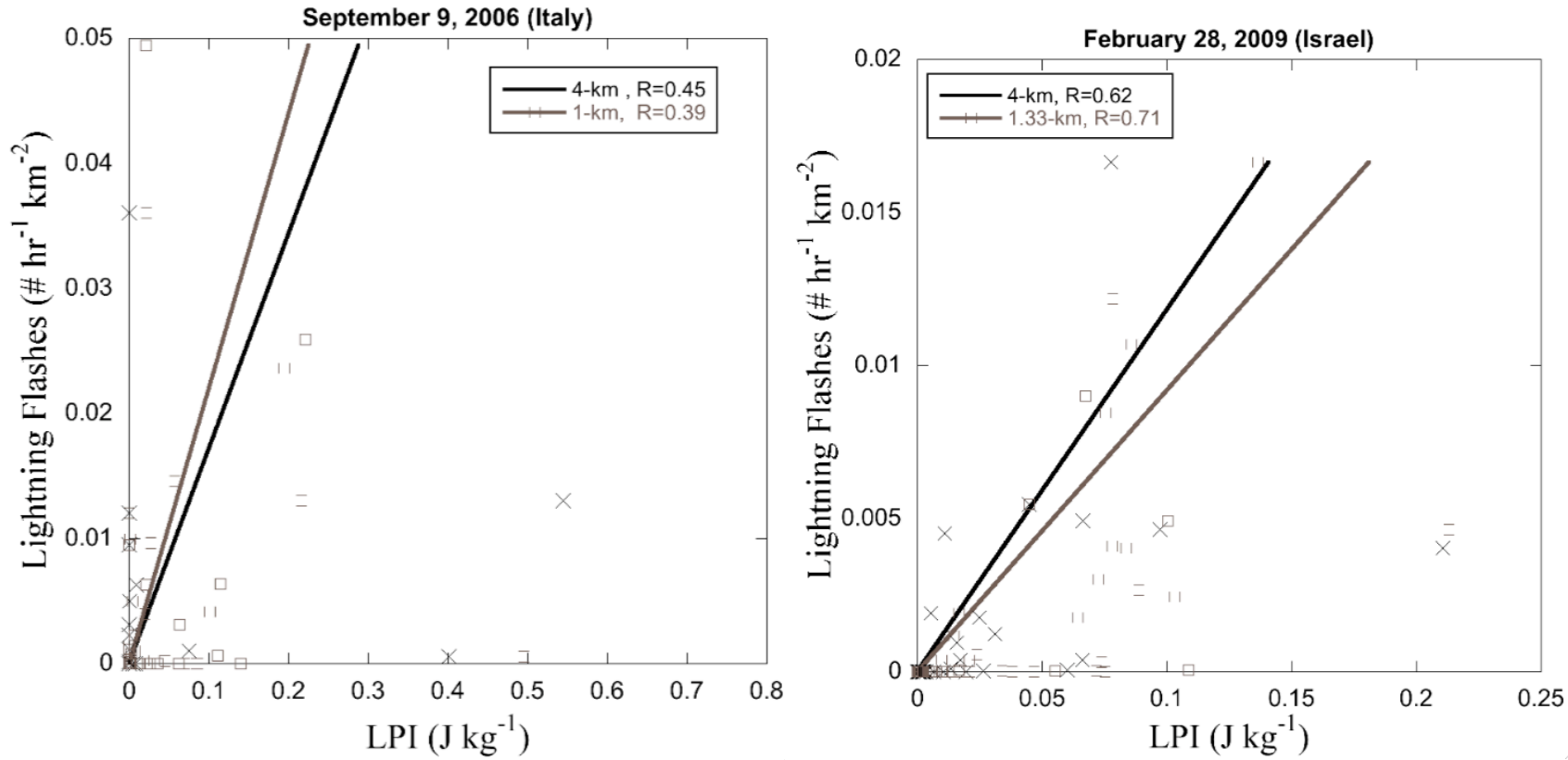

Fig. 2. Correlations between the value of the calculated (time averaged) LPI in 4-km and 1-km grids and the accumulated lightning flash numbers in the respective areas and times for the two case studies Italy (left) and Israel (right). 

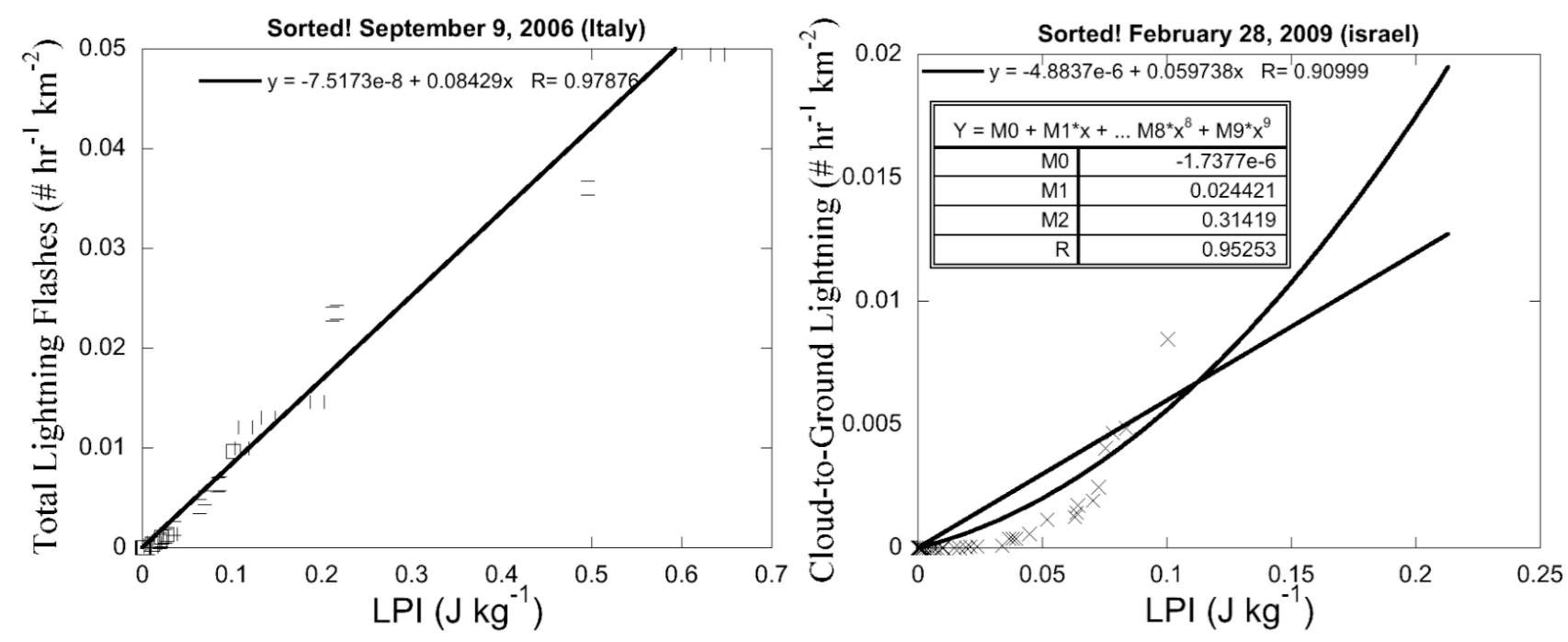

Fig. 3. Lightning versus LPI for the two case studies Italy (left) and Israel (right) averaged for $36 \mathrm{~km}$ grid points.

timing and location of predicted lightning producing clouds. For example, a visual inspection of Fig. 1 suggests that both the $1.33 \mathrm{~km}$ and $4 \mathrm{~km}$ simulations over-estimate the spatial extend of high LPI values compared to the coverage of high numbers of accumulated total lightning, which suggests that the linear relationship shown in Fig. 3 for Case A should probably be steeper than shown.

\section{Concluding remarks}

The Lightning Potential Index (LPI) is a measure of the potential for charge generation and separation that leads to lightning flashes in convective thunderstorms, calculated from the WRF model microphysical and dynamical fields. The WRF model was used to simulate two heavy-rain events which had significant lightning activity. The model reproduced the general characteristics of convection and the spatial distribution of lightning activity. When averaged over a $36 \times 36 \mathrm{~km}^{2}$ area, the results show robust relationships between the values of LPI and the observed lightning activity. It can be concluded that the usage of the Lightning Potential Index (LPI) in operational 4-km grid scale models can yield valuable information on major areas where convection is expected and where the potential for thunderstorms is large.

Maps of LPI and predicted lighting density can be produced in regular operational runs of short range forecasting models and to serve as a valuable early warning tool for relevant users. For instance, the observed lightning fields can be compared to the model predicted LPI (over shorter time periods than used in this analysis). High correlations between the two would suggest that the model predicted evolution of LPI should be considered as a potential warning for the short-term future evolution of lightning. Moreover, such high correlations would indicate that the model predicted rainfall should be treated with greater confidence than without the knowledge of predicted LPI. Spatial variations between the locations of model predicted LPI (and the associated heavy rain) would suggest that potential flash-flood watches for other locations should be upgraded to warnings and viceversa.

Acknowledgements. This research was conducted in the framework of the FLASH project, contract number 036852 of the EU 6th Framework Program.

Edited by: S. Michaelides, K. Nicolaides, and A. Orphanou Reviewed by: O. Altaratz and V. Kotroni

\section{References}

Altaratz, O., Levin, Z., Yair, Y., and Ziv, B.: Lightning Activity over Land and Sea on the Eastern Coast of the Mediterranean, Mon. Weather Rev., 131, 2060-2070, 2003.

Deierling, W., Petersen, W. A., Latham, J., Ellis, S., and Christian, H. J.: The relationship between lightning activity and ice fluxes in thunderstorms, J. Geophys. Res., 113, D15210, doi:10.1029/2007JD009700, 2003.

Deierling, W. and Petersen, W. A.: Total lightning activity as an indicator of updraft characteristics, J. Geophys. Res., 113, D16210, doi:10.1029/2007JD009598, 2008.

Dudhia, J., Hong, S.-Y., and Lim, K.-S.: A new method for representing mixed-phase particle fall speeds in bulk microphysics parameterizations, J. Meteorol. Soc. Jpn., 86, 33-44, 2008.

Kotroni, V. and Lagouvardos, K.: Lightning occurrence in relation with elevation, terrain slope and vegetation cover over the Mediterranean, J. Geophys. Res.-Atmos., 113, D21118, doi:10.1029/2008JD010605, 2008.

Lagouvardos, K., Kotroni, V., Betz, H.-D., and Schmidt, K.: A comparison of lightning data provided by ZEUS and LINET networks over Western Europe, Nat. Hazards Earth Syst. Sci., 9, 
1713-1717, 2009,

http://www.nat-hazards-earth-syst-sci.net/9/1713/2009/.

Lynn, B. H. and Yair, Y.: Lightning Potential Index: A new tool for predicting the lightning density and the potential for extreme rainfall. Geophysical Research Abstracts, EGU General Assembly, Vienna, Vol. 10, EGU2008-A-01571, SRef-ID: 16077962/gra/EGU2008-A-01571, 2008.

MacGorman, D. R. and Rust, W. D.: The Electrical Nature of Storms, Oxford Univ. Press, 422 pp., 1998.

MacGorman, D. R., Cohen, A., Mansell, T., and Ziegler, C.: Flash rate, electrical, microphysical, and dynamical relationships across a simulated storm spectrum, Eos Trans. AGU, 89(53), Fall Meet. Suppl., Abstract AE24A-06, 2008.

Petersen, W. A. and Rutledge, S. A.: On the relationship between cloud-to-ground lightning and convective rainfall, J. Geophys. Res., 103, 14025-14040, 1998.

Saunders C. P. R. : Charge separation mechnisms in clouds, Space Sci. Rev., 137(1-4), 335-354, doi:10.1007/s11214-008-09345-0, 2008.
Sherwood, S. C., Phillips, V. T. J., and Wettlhaufer, J. S.: Small ice crystals and the climatology of lightning, Geophys. Res. Lett., 33, L05804, doi:10.1029/2005GL025242, 2006.

Skamarock, W. C., Klemp, J. B., Dudhia, J., Gill, D. O., Barker, D. M., Wang, W., and Powers, J. G.: A description of the advanced research WRF version 2, NCAR Technical Note 468+STR, June 2005, revised, January, 2007.

Thompson, G., Rasmussen, R. M., and Manning, K.: Explicit forecasts of winter precipitation using an improved bulk microphysics scheme, Part I: Description and sensitivity analysis, Mon. Weather Rev., 132, 519-542, 2004.

Wiens, K. C.: Summary of Colorado State University's LMARelated Observations from STEPS, Eos Trans. AGU, 89(53), Fall Meet. Suppl., Abstract AE24A-07, 2008.

Yair, Y., Lynn, B., Price, C., Kotroni, V., Lagouvardos, K., Morin, E., Mugnai, A., and Llasat, M. C.: Predicting lightning density in Mediterranean storms based on the WRF model dynamic and microphysical fields, J. Geophys. Res., in press, 2010. 